\title{
Advances in Chitosan Material and its Hybrid Derivatives: A Review
}

\author{
Duck Weon Lee ${ }^{1}$, Hosun $\mathrm{Lim}^{2}$, Ha Na Chong ${ }^{3}$ and Woo Sub Shim*,
}

\author{
${ }^{1}$ Fiber and Polymer Science Program, ${ }^{2}$ Textile Technology Management Program, ${ }^{3}$ Polymer and Color Chemistry \\ Program, College of Textiles, North Carolina State University, Raleigh, NC 27695-8301, USA
}

\begin{abstract}
Chitosan is a safe and friendly substance for the human organism; therefore, it has become of great interest not only as an underutilized resource, but also as a new functional material of high potential in various fields. Some unique properties make chitosan an excellent material for the development of new industrial applications and recent progress in chitosan material is quite noteworthy. In this review, we mainly take a closer look at various chitosan applications and intend to provide interdisciplinary insight in the scientific knowledge immediately usable to realize fabrications. In addition, based on current research and existing products, some new approaches in this fascinating area are thoroughly discussed.
\end{abstract}

Keywords: Chitosan, application, agricultural, water treatment, food, medical, biotechnological, fabrication.

\section{INTRODUCTION}

Chitosan is a polysaccharide which is derived from chitin (Fig. 1) [1]. Chitin is the second most abundant polysaccharide in the world, dominated only by cellulose [2]. This renewable resource is found in many naturally occurring organisms such as fungi, yeast, and is the principal component in the exoskeleton of sea crustaceans such as shrimp and crab. Chitin has a homogeneous chemical structure made up of 1-4 linked 2-acetamido-2-deoxy- $\beta$-Dglucopyranose. Although chitin is found naturally in large amounts through many sources, chitosan is only found in some fungi with limited quantities. The chitosan used in industrial applications is typically derived from chitin through the use of chemical or enzymatic treatments of the shells of shrimp or crab secured from the waste products of the crabbing and shrimping industries. Chitosan is the form of chitin which has been deacetylated to at least $50 \%$ of the free amine form, which has a heterogeneous chemical structure made up of both 1-4 linked 2-acetamido-2-deoxy$\beta$-D-glucopyranose as well as 2 -amino-2-deoxy- $\beta$-Dglucopyranose. Recently, much attention has been paid to chitosan as a potential polysaccharide resource Although several efforts have been reported to prepare functional derivatives of chitosan by chemical modifications [3-5] very few attained solubility in general organic solvents $[6,7]$ and some binary solvent systems [8-10]. Chemically modified chitin and chitosan structures resulting in improved solubility in general organic solvents have been reported by many workers [11-20]. We review mainly three areas that are enabled by the use of advanced materials: water treatment, medical, and biotechnological applications. Also, we summarize recent results suggesting the hybrid chitosan material may be a key enabling material for various industries.

*Address correspondence to this author at the Fiber and Polymer Science Program, College of Textiles, North Carolina State University, Raleigh, NC 27695-8301, USA; Tel: 1-919-610-9679; Fax: 1-919-515-6532;

E-mail: jacob0720@gmail.com

\section{PROPERTIES}

The properties of chitosan are greatly affected by the conditions under which it is processed, because it is the process conditions that control the amount of deacetylation that occurs. The degree of deacetylation controls the amount of free amino groups in the polymer chain. The free amino groups give chitosan its positive charge. The amino group along with the hydroxyl group gives chitosan its functionality which allows it to be a highly reactive polysaccharide. Chitosan's positive charge allows it to have many electrostatic interactions with negatively charged molecules. The processing conditions as well as the amount of functional groups created by deacetylation allow for side group attachment, which then effects crystallinity which directly relates to chitosan's ability to solubilize in acidic aqueous solutions, which is an important aspect of chitosan's processability [21-23].

Chitosan has many physicochemical (reactive $\mathrm{OH}$ and $\mathrm{NH}_{2}$ groups) and biological (biocompatible, biodegradable) properties that make it an attractive material for use in various applications. These properties include: biodegradability, lack of toxicity, anti-fungal effects, wound healing acceleration, and immune system stimulation [2426]. Because of chitosan's biological and chemical properties it has the ability to bind to particular materials including cholesterols, fats, proteins, metal ions, and even tumor cells. This allows chitosan to be used as a chelating agent in various applications [27].

\subsection{Degradation}

Chitosan can be degraded through several means and because its degradation rate is inversely proportional to the degree of crystallinity and consequently the amount of deacetylation, its degradation rate is able to be engineered by controlling the amount of deacetylation that occurs during processing. At temperatures above $280{ }^{\circ} \mathrm{C}$ thermal degradation occurs and polymer chains rapidly break down. Enzymatic degradation is the leading means of controlling 
the break down of chitosan. A wide array of hydrolytic enzymes, such as lysozyme, which is the primary enzyme responsible for degradation of chitosan and is found in the lyphoid systems of humans and animals, can be used to naturally degrade chitosan $[21,23]$. Within the body the degradation of chitosan leads to the release of aminosugars, which can be easily processed and released through the metabolic system. Degradation is an important property to understand so that processing and end applications can be designed accordingly [26].

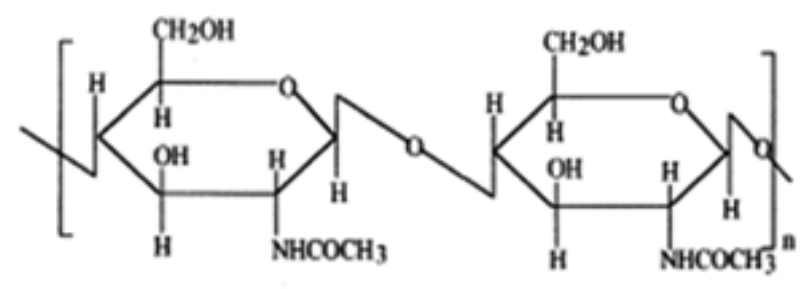

(a) Chitin

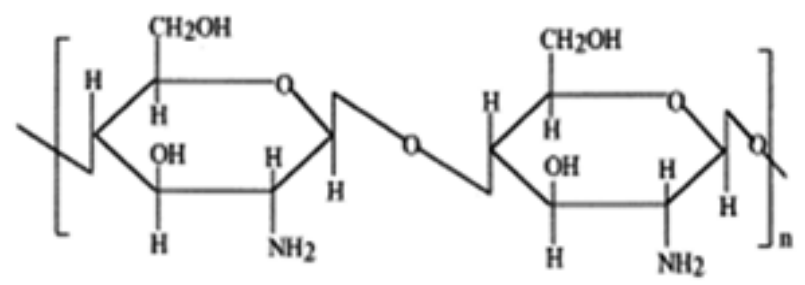

(b) Chitosan

Fig. (1). Chemical structures of (a) chitin and (b) chitosan.

\subsection{Molecular Weight}

Chitosan molecular weight distributions have been obtained using HPLC technique [28]. In addition, the weight-average molecular weight $\left(M_{\mathrm{w}}\right)$ of chitosan has been determined by light scattering [29]. Viscometry is a simple and rapid method for the determination of molecular weight. The charged nature of chitosan in acid solvents and chitosan's propensity to form aggregation complexes require care when applying these constants. Furthermore, converting chitin into chitosan lowers the molecular weight, changes the degree of deacetylation, and thereby alters the charge distribution, which in turn influences the agglomeration. The weight-average molecular weight of chitin is $1.03 \times 10^{6}$ to $2.5 \times 10^{6}$, but the $N$-deacetylation reaction reduces this to $1 \times 10^{5}$ to $5 \times 10^{5}$ [30].

\subsection{Solvent Properties}

Chitin and chitosan degrade before melting, which is typical for polysaccharides with extensive hydrogen bonding. This makes it necessary to dissolve chitin and chitosan in an appropriate solvent system to impart functionality. For each solvent system, polymer concentration, $\mathrm{pH}$, counterion concentration and temperature effects on the solution viscosity must be known. As a general rule, the maximum amount of polymer is dissolved in a given solvent towards a homogeneous solution. A coagulant is required for polymer regeneration or solidification. The nature of the coagulant is also highly dependent on the solvent and solution properties as well as the polymer used
$[31,32]$. Water-soluble chitin, however, can be prepared by either homogeneous deacetylation of chitin [33] or homogeneous $\mathrm{N}$-acetylation of chitosan [34, 35]. Water solubility is obtained only when the deacetylation degrees of chitin is about 0.5 . It should be emphasized that the watersoluble chitin is obtained by homogeneous reaction instead of heterogeneous reaction. The former treatment gives a random copolymer of $\mathrm{N}$-acetyl-Dglucosamine and Dglucosamine units, whereas the latter one produces a block copolymer of these two units. X-ray diffractometry revealed that the random copolymer was almost amorphous, but the block copolymer was highly crystalline, although the degree of deacetylation of the two polymers is the same. Kurita et al. [33-35] concluded that the water solubility was attributed to the greatly enhanced hydrophilicity resulting from the random distribution of acetyl groups and the destruction of the tight crystalline structure of chitin.

\section{CURRENT APPLICATIONS}

Due to chitosan's many attractive properties such as reactivity, biodegradability, natural origin, abundance, etc., it has many areas of application including: waste and water treatment, medical, biotechnological areas, and fabrications.

\subsection{Water Treatment Applications}

Chitosan's functional groups and natural chelating properties make chitosan useful in wastewater treatment by allowing for the binding and removal of metal ions such as copper, lead, mercury, and uranium from wastewater. It can also be utilized to remove dyes and other negatively charged solids from wastewater streams and processing outlets. Chitosan grafted with poly(acrylonitrile) has been further modified to yield amidoximated chitosan [36] a derivative having a higher adsorption for $\mathrm{Cu}^{2+}, \mathrm{Mn}^{2+}$, and $\mathrm{Pb}^{2+}$, compared to cross-linked chitosan. The adsorption capacity had a linear dependence on $\mathrm{pH}$ in cases of $\mathrm{Cu}^{2+}$ and $\mathrm{Pb}^{2+}$. However, a slight decrease in the adsorption capacity was observed in case of $\mathrm{Zn}^{2+}$ and $\mathrm{Cd}^{2+}$ [37]. Chitosan has been modified with different mono as well as disaccharides. Others [38] have also reported the metal uptake abilities of macrocyclic diamine derivative of chitosan. The polymer has high metal uptake abilities, and the selectivity property for the metal ions was improved by the incorporation of azacrown ether groups in the chitosan. The selectivity for adsorption of metal ions on polymer was found to be $\mathrm{Ag}^{+}>\mathrm{Co}^{2+}>\mathrm{Cr}^{3+}$. These results reveal that the new type chitosan-crown ethers will have wide ranging applications for the separation and concentration of heavy metal ions in environmental analysis. In addition, a novel type cellulosebased ion exchanger, chitosan-g-carboxymethylcellulose (CS-g-CMC) (Fig. 2), has been successfully prepared by thermal graft copolymerization for removal heavy metal ions from aqueous solutions. The adsorption properties of the grafted copolymer relied on $\mathrm{pH}$ value, $\mathrm{CS}$ content and reaction temperature. The high adsorption selectivity and good kinetic properties of metal ions indicated that the novel CS-g-CMC ion exchanger could be used to remove the heavy metal ions from aqueous solution [39]. Cyclodextrin (CD) containing polymers, due to their ability to form hostguest complexes, are compound of interest in many applications; from the stabilization and the controlled release of active components in formulation to extraction and 
separation processes. The chitosan grafted with $\beta$-CD derivatives have ability to form complexes with a variety of other appropriate compounds, to develop novel sorbent materials [40-43].

\subsection{Medical Applications}

Due to chitosan's ability to function in many forms it has many areas of interest within the medical industry including: orthopedic, tissue engineering, wound healing, drug delivery, and surgical adhesion [25-27].

\subsubsection{Orthopedics}

Chitosan's functional groups allow it to interact with many materials, which allow it to be used in conjunction with materials such as hydroxyapatite, or other calciumbased minerals to form composites that have multiple applications within the orthopedic and periodontal industries. These calcium-chitosan composites can be used as a coating in conjunction with joint prostheses. As the chitosan is degraded, new bone can be deposited adjacent to the prosthesis to stabilize the implant within bone. An additional use for chitosan in orthopedics includes a direct replacement of bone or hard tissue. It is also a natural bioadhesive used to improve bone cement which is used to secure implants as well as to fill bone cavities [25-27].

\subsubsection{Tissue Engineering}

Chitosan's ability to be manufactured in many forms such as fibers, filaments, films, sponges, gels, and composites make it easily engineered for particular end applications or for use within a particular area of the body or in conjunction with a certain tissue. In this respect, there are three majors to be considered for the success of tissue regeneration: cells, scaffold, and cell scaffold interaction shown in Fig. (3).

Chitosan can be used to make three-dimensional scaffolds that act as an artificial extracellular matrix, which can be resorbed by the body over time as new tissue is formed and a natural extracellular matrix is formed helping to further integrate new tissue into the body [24, 27]. In addition, chitosan is used in this application due to its biocompatibility, ability to have an engineered degradation rate, antimicrobial activity, ability to interact with other materials to form composites, and its ability to interact with and encourage cellular attachment and growth [44-46]. Its mechanical properties can be enhanced or reduced to closely resemble the properties of the tissue it is replacing; for example it can be made to support hard tissues such as bones or cartilage or soft tissues such as muscles and blood vessels. It also has the ability to attract glycosaminoglycans which enables chitosan to collect growth factors which enhances cell attachment and proliferation [23].

\subsubsection{Wound Healing}

Chitosan enhances the functions of cells that immerge during the inflammatory response, while accelerating the migration of these cells to the injured area $[47,48]$. These cells such as macrophages kill microorganisms, remove dead

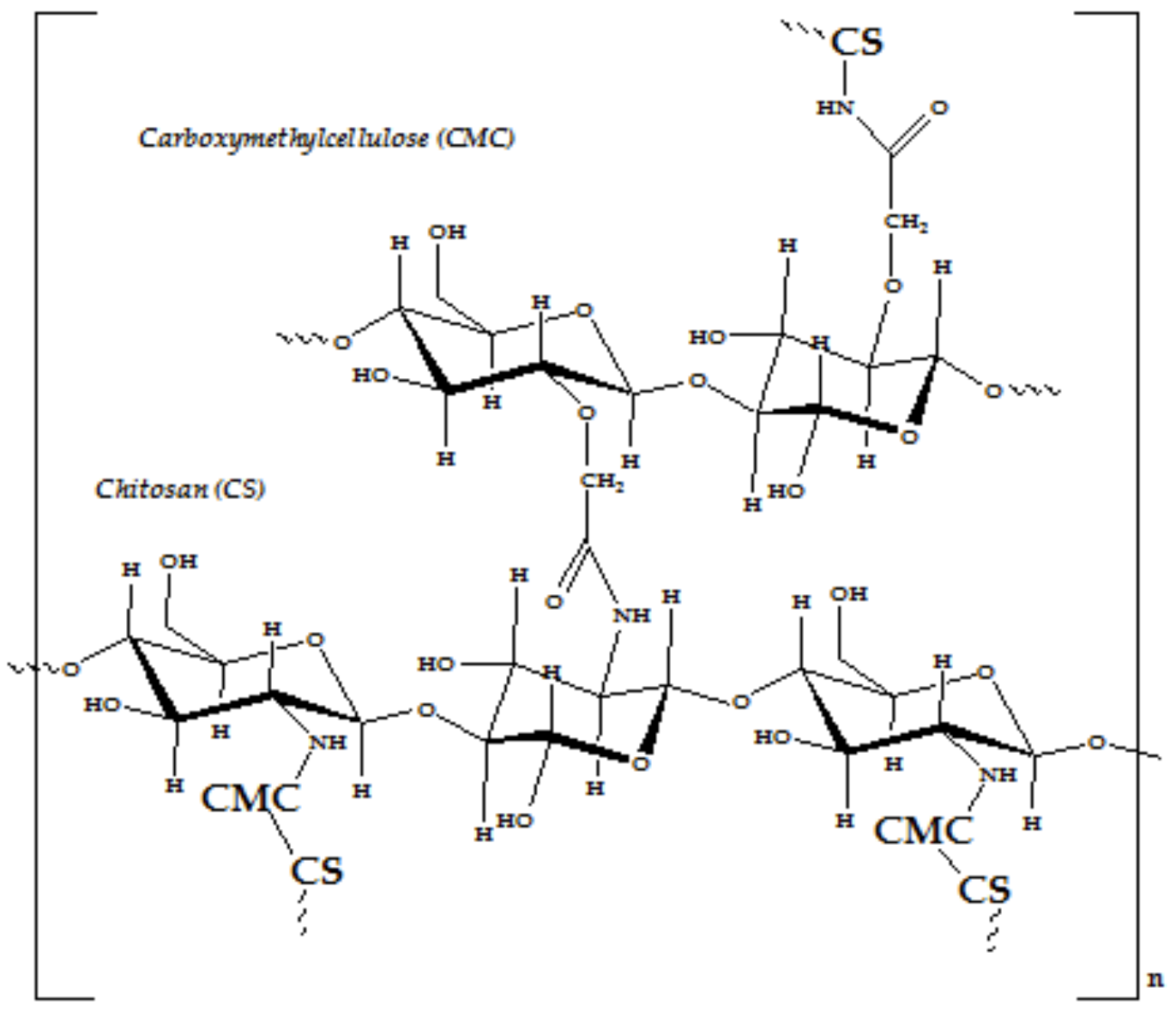

Fig. (2). Chemical structure of CS-g-CMC biomaterials [39]. 

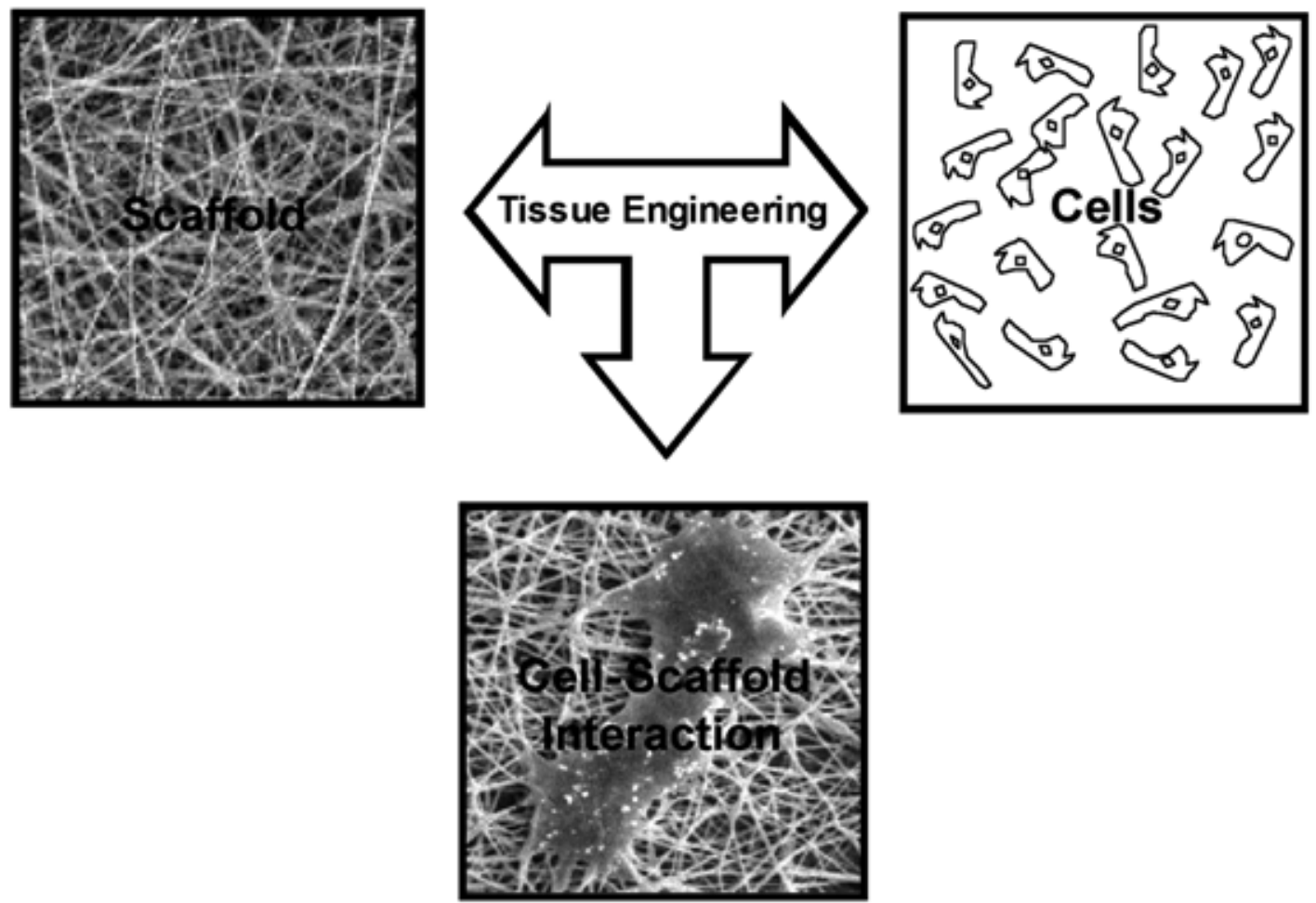

\section{Highly compatible cell and scaffold interaction using nanofibers}

Fig. (3). Main applications of tissue engineering [82].

cells, and stimulate the other immune system cells, which improve overall healing by reducing the opportunity for infection. Chitosan's positive charge allows for electrostatic interactions with glycosaminoglycans, which attract growth factors that enhance cell growth. Its cationic nature also allows it to associate with anions that are connected with the bacterial cell wall, which retards the bacteria's ability synthesize [23]. Several chitosan's possible material forms can be used independently, such as hydrogels, while others can be used in conjunction with traditional bandages to provide a wound protection from the outside elements, while maintaining a moist environment that promotes healthy healing. A bandage material that does not require removal due to its ability to safely biodegrade within the body is an additional potential use that makes chitosan an appealing wound healing material choice [27, 47].

\subsubsection{Drug Delivery}

The use of polymers such as chitosan to deliver drugs to their appropriate location within a biological system is an area of great interest. Chitosan is able to be degraded within a biological system over time, and furthermore that degradation rate is easily engineered based on the amount of deacetylation that occurs during processing. This allows drugs to be released into the body in a controlled manor to be as effective as possible. The free amine group that gives chitosan a positive charge is imperative to drug delivery for it is this charge that permits it to interact with negatively charged drugs, polymers, and bioactive molecules. This is also the feature that enables chitosan to adhere to mucous membranes making it especially useful for drug delivery via the respiratory system [49]. Its ability to be used in various forms such as gels, copolymers, etc. is another characteristic that makes chitosan an attractive material for drug transport. It can form colloidal particles and entrap negatively charged molecules through several means such as chemical and ionic crosslinking. Chitosan's versatility along with its other biological properties including biocompatibility begets a material well suited for drug delivery [50].

\subsubsection{Surgical Adhesion}

Biological adhesives are used for tissue adhesion, hemostasis, and sealing of the leakage of air and body fluids during surgical procedures. An adhesion is the formation of fibrous tissue that causes internal organs to be bound together in an unnatural fashion. These adhesions often occur during pelvic, abdominal or gynecological surgeries such as hysterectomies, cesarean sections, colectomies, and hernia repairs [51]. After these procedures are completed and the body is attempting to heal its self through normal wound healing responses, swelling occur causing organs to be in closer proximity to one another than under normal internal conditions. Another component of natural wound healing is for the body to deposit fibrin to help repair damaged or injured tissues. This type of tissue formation can lead to infertility when adhesions twist ovaries and or tubes resulting in the blocking of the egg to the uterus. A photocrosslinkable chitosan to which both azide and lactose moieties were introduced (Az-CH-LA) was prepared as a biological adhesive for soft tissues and its effectiveness was compared with that of fibrin glue [52]. A cytocompatible chitosan solution that is space-filling, gels within minutes, and adheres to cartilage and bone in situ was developed [53]. 


\subsection{Biotechnological Applications}

\subsubsection{Cell-Stimulater}

Soyabeans were coated with a thin layer of depolymerized chitin, carboxymethyl (CM)-chitin and hydroxyethyl (HE)-chitin, and the seeds were cultured in the field. It was observed that the seed chitinase increased 1.52.0 -fold, the seed germination rate increased by $6 \%$, the pod number increased by $9 \%$, the plant dry weight increased by $8 \%$, and the crop yield also increased by $10-12 \%$ over the control [54]. Dressing with chitin films, sponges and fibres enhanced chitinase activity in tree-bark tissues around wounds up to four-fold over the control. The chitin films, which were implanted in or used to dress the tree-bark tissues, were digested within 4 to 24 weeks thereafter. The fate of N-acetyl-D-glucosamine in plant tissue is unknown. Phenylalanine ammonia-lyase was stimulated by treatment with chitin, and lignin formation in the plant increased. As a result, wound healing was increased [55].

\subsubsection{Fat-Net}

Many supplements can help in the fat reduction process, including pyruvate and chitosan. Pyruvate, found in red apples, some types of cheese, and red wine, stimulates fat loss and boosts exercise performance. Chitosan attaches itself to fat in the stomach before it is digested, thus trapping the fat and preventing its absorption by the digestive tract. Fat in turn binds to the chitosan fibre, forming a mass which the body cannot absorb, and which is eliminated by the body. Chitosan fiber differs from other fibers in that it possesses a positive ionic charge, which gives it the ability to bond chemically with the negatively charged lipids, fats and bile acids $[46,56,57]$.

\section{FABRICATIONS}

\subsection{Electrospinning}

Electrospinning is a straightforward, cost-effective, versatile technique employing electrostatic forces to produce polymer fibers, ranging in diameter from a few microns down to tens of nanometers. Researchers in the past have made attempts to electrospin chitosan in order to further utilize this material [56-66]. A basic apparatus for electrospinning consists of three major components: a spinneret, a fiber collector, and a high-voltage power supply as shown in Fig. (4). Chitosan produces many challenges in being electrospun largely due to its high solution viscosity. Chitosan's rigid D-glucosamine structures, high crystallinity and ability to hydrogen bond lead to poor solubility in common organic solvents [59]. Chitosan is a cationic polymer, polyelectrolyte, and subject to the polyelectrolyte effect where in aqueous solution, chitosan's polymer coils are greatly expanded by the presence of charged groups and if the solution is free of added electrolytes the polymer coil contracts as the polymer concentration increases [58].

The combination of these properties makes it difficult to create a chitosan-based solution with a high concentration of polymer that has a low enough viscosity to be able to be electrospun. However, since 2004 there have been reports of electrospinning chitosan in blended solutions with varying degrees of success [56-66]. Ohkawa et al. [62] electrospun chitosan10/PVA and chitosan100/ PVA at the same time that they spun pure chitosan 10 . With a $30 / 70$ chitosan10/PVA ratio, fibers with an average diameter of $120 \mathrm{~nm}$ were fabricated; thicker fibers were observed when higher ratios were employed. As a comparison, PVA/deionized $\mathrm{H}_{2} \mathrm{O}$ electrospun without additional polymers had an average

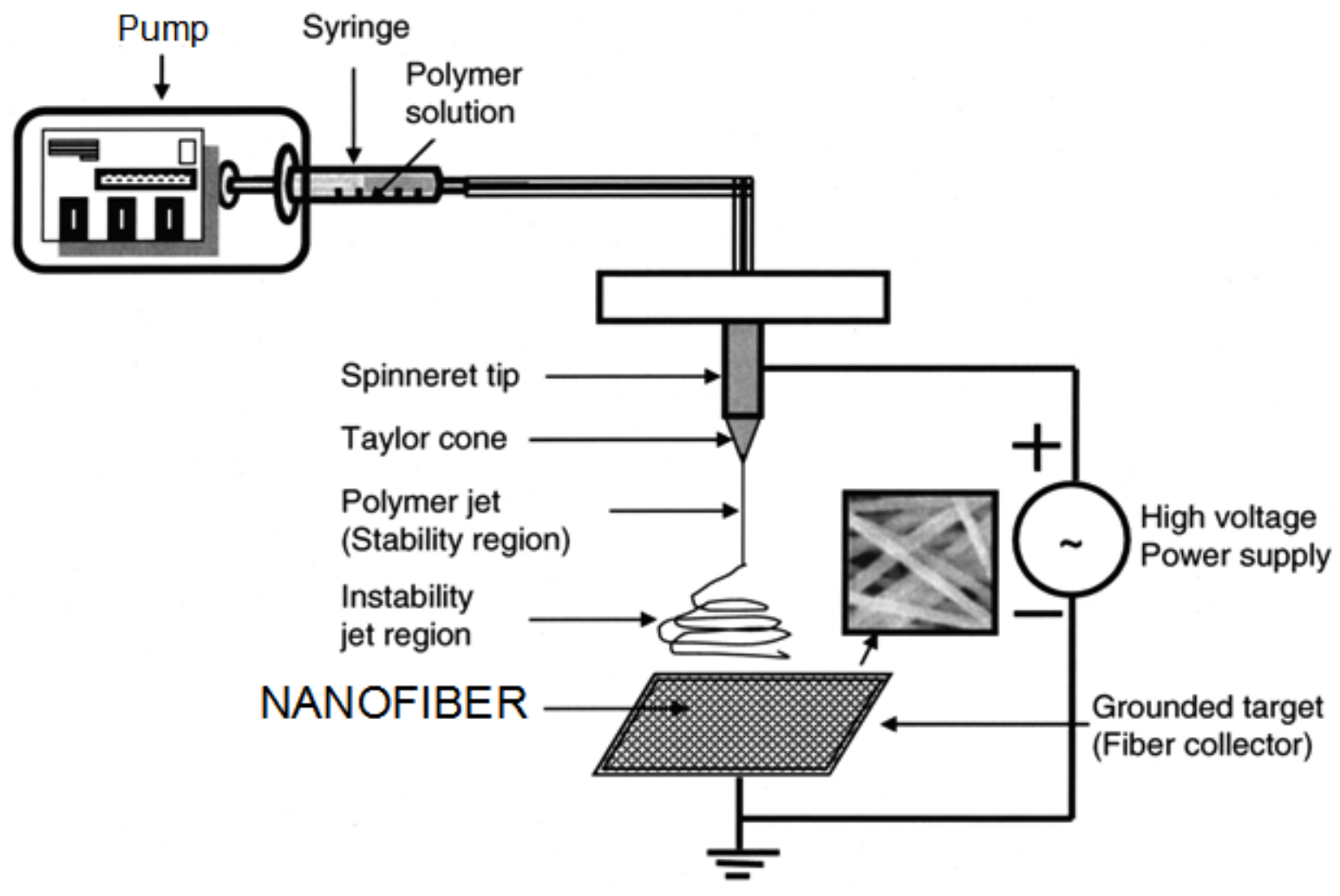

Fig. (4). Schem of electrospinning system. 
diameter of $470 \mathrm{~nm}$. Zhang et al. [67] also spun 40/60 chitosan/PVA fibers in $2 \%$ AA solutions. Transmission electron microscopy (TEM) and energy dispersive spectroscopy (EDS) identified that the as-spun fibers and beads both contained chitosan. They believe that chitosan/PVA nonwovens might be suitable for wound dressings based on their high water up-take capabilities. Zhou et al. [68, 69] electrospun fibers from chitosan/PVA in aq acrylic acid (AcrA) solutions160 and later thermally crosslinked the fibrous mats using triethylene glycol dimethcrylate (TEGDMA) for $2 \mathrm{~h}$ at $80{ }^{\circ} \mathrm{C}$ [70]. Due to the polyelectrolytic nature of chitosan, it has a high viscosity in dilute aqueous solutions. Therefore, it can be desirable to use chitosan as a thickener, especially since it is compatible with other biocompatible polymers such as PVA [70, 71] and PEO [72]. Sometimes beads are observed when electrospinning. To counter this, additives such as salts 150 or surfactants [73] can be used. Similarly, cationic and anionic polyelectrolytes [74] could increase the conductivity of a solution and thus decrease fiber diameter. Lin et al. [75, 76] electrospun a combination of $1 \%$ chitosan with $5-8 \%$ PVA. Jia et al. [76] and Deitzel [77] additionally noted that electrospinning restricts the formation of a crystalline microstructure due to (1) the rapid solidification of the stretched molecular chains and (2) high elongation rates.

Duan et al. [64] noted that with a mass ratio of chitosan/PEO of $1 / 2$ or $1 / 1$, conductivity, surface tension, and solution viscosity enhanced electrospinning. FTIR, $x$-ray photoelectron spectroscopy (XPS), and differential scanning calorimetry (DSC) determined that the smaller fibers were primarily composed of chitosan while larger fibers were mainly composed of PEO. Around the same time, Spasova et al. [63] published the successful electrospinning of chitosan/PEO when the mass ratios were equal to or less than one. With increased amounts of chitosan, the fiber diameter increased. Bhattrai et al. [46] added PEO to reduce the viscosity of chitosan solutions, therefore a higher polymer concentration would be spinnable. Chitosan/PEO mats (9/1) retained structural integrity in $\mathrm{H}_{2} \mathrm{O}$ and promoted good adhesion of chondrocyte and osteoblast cells, and might be appropriate for bone tissue engineering. Bhattrai et al. noted that the solubility of PEO in water is desirable when fast degradation times are needed, such as for controlled drug release. Alternatively, when mechanical stability is necessary, like for tissue repair and remodeling, where cell attachment, differentiation, and growth are needed, a scaffold primarily composed of chitosan is more suitable.

Poly(ethylene terephthalate) (PET) is common in the textile and plastic industry due to its antibacterial properties $[78,79]$ mechanical properties, and fair biocompatibility. Jung et al. [80] fabricated chitosan/PET mats for medical applications. Using TFA/HFIP as the solvent, chitosan/PET, and chitin/PET were electrospun and antibacterial activity experiments were conducted. The mats that contained chitosan inhibited the growth much more effectively than both the pure PET and the chitin/PET non-wovens. The collagen-chitosan complex nanofibers have been reported for the first time by electrospinning and designed to mimic the native extracellular matrix for tissue engineering and to develop functional biomaterials [81].

\section{2. pH Responsive}

Fig. (5) indicates that $\mathrm{pH}$ substantially alters the charged state and properties of chitosan. At low $\mathrm{pH}$, these amines are protonated and positively charged, and chitosan is a watersoluble cationic polyelectrolyte. At high $\mathrm{pH}$, chitosan's amines become deprotonated and the polymer loses its charge and becomes insoluble. Importantly, chitosan's $\mathrm{p} K_{\mathrm{a}}$ is near neutrality [84-88], and the soluble-insoluble transition occurs at pHs between 6 and 6.5 which is a particularly convenient range for biological applications. In contrast, polylysine has a considerably higher $\mathrm{p} K_{\mathrm{a}}(\approx 10)$ and exists only as a polycation at $\mathrm{pHs}$ where biological systems are stable. At high $\mathrm{pH}$, chitosan's electrostatic repulsions are reduced allowing the formation of inter-polymer associations (e.g., liquid crystalline domains or network junctions) that can yield fibers, films, or hydrogels, depending on the conditions used to initiate the soluble-insoluble transition [89]. In conclusion, Fig. (5) indicates that chitosan's amines are reactive allowing a range of chemistries to be employed to graft substituents to functionalize chitosan or to cross-link the chitosan backbone to confer elasticity [90].

\subsection{External Stimuli}

There is an emerging trend to use a broader range of external stimuli to direct components to assemble and to guide spatial ordering. As suggested in Fig. (6), this trend is emerging because of the increasing capabilities to construct hybrid materials that consist of one component, which is typically an inorganic nanoparticle, which confers responsiveness to a specific stimulus. Currently, hybrid materials composed of nanoparticles and biological components are under intense study for various applications [91]. Lvov and co-workers [92] used layer-by-layer (LbL) assembly to create core-shell particles with a coimmobilized enzyme and magnetic nanoparticle. These hybrid particles retained both their biocatalytic activity and their responsiveness to locally applied magnetic fields. Willner and co-workers [93] created a hybrid material from a biological sensing component and a magnetic particle. This hybrid allowed biomolecular recognition to be detected by the magnetomechanical deflection of a cantilever. Although these examples illustrate the potential of directing the assembly of bio-nano hybrid materials, there are also exciting advances in the synthesis of such bio-nano hydrid materials. In particular, molecular biological methods are being applied to discover peptide sequences that allow biological components such as proteins, virus particles, or cells to selectively recognize and couple to nanoparticles [94-97].

\subsection{Electrical Stimuli}

The potential utility of chitosan's electrodeposition can be illustrated by a couple of examples. Fig. (7a) illustrates that chitosan can mediate the spatially selective assembly of nanoparticles that are suspended in a chitosan solution. To demonstrate this capability, $100 \mathrm{~nm}$ fluorescent latex spheres were suspended in a $1 \%$ chitosan solution at $\mathrm{pH} 5$. Fig. (7b) shows the silicon wafer fabricated with $20 \mu \mathrm{m}$ patterned gold lines that was immersed in the chitosan-containing suspension and biased to serve as the cathode. The fluorescence photomicrograph and image analysis in Fig. (7c) show that the $100 \mathrm{~nm}$ particles were assembled onto the 


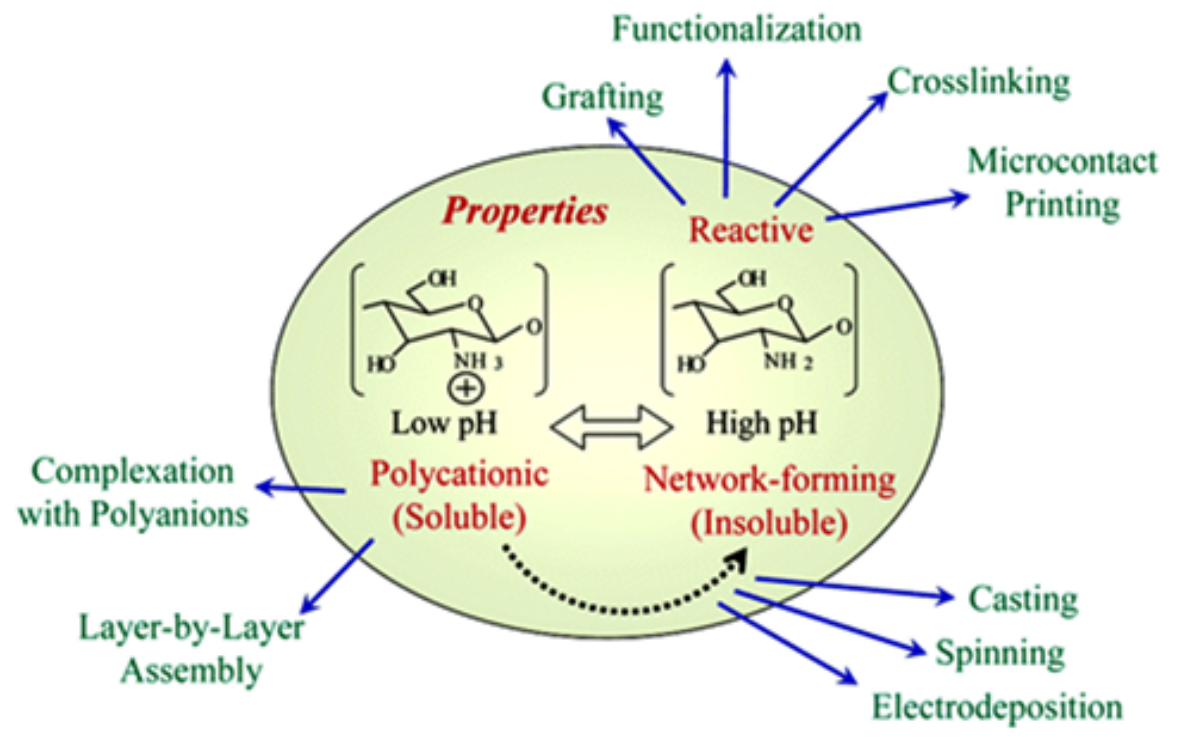

\section{Fabrication of chitosan under $\mathrm{pH}$ values}

Fig. (5). Schematic illustrating the adaptability of chitosan for fabrication: Less than about 6, chitosan's amines are protonated conferring polycationic behavior to chitosan. Above about 6.5, chitosan's amines are deprontonated and reactive and chitosan can undergo interpolymer associations that can lead to fiber and network formation [83].

\section{Nano-Bio Combined Derivatives}

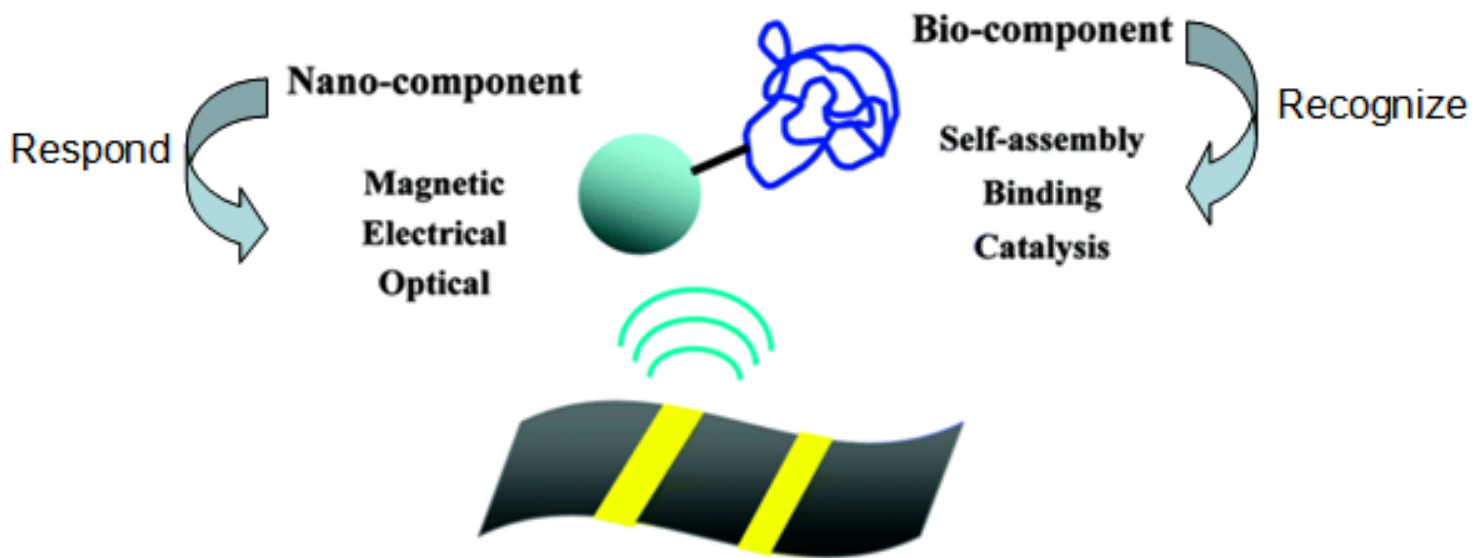

\section{Microfabricated Device}

Fig. (6). Hybrid combined derivatives can be directed to assemble if one component can respond to an external stimulus. Microfabrication allows devices to be constructed that can apply a variety of external stimuli with spatial and temporal control [83].

cathode surface with high lateral resolution, for example, in the $x-y$ directions. Control experiments demonstrate that chitosan is required for nanoparticle assembly, whereas further analysis indicated that the nanoparticles are entrapped throughout the chitosan matrix, for instance, in the $z$ direction. Potentially chitosan-mediated electrodeposition provides a means to assemble nanoscale particles into higher-order structures, a requirement that is necessary to exploit many of the unique properties of nanoparticles [98].

\subsection{Enzymatic Assembly}

Fig. (8) shows two important features of the tyrosinaseinitiated grafting to chitosan. The scheme in Fig. (8a) illustrates that tyrosinase's substrate range is not limited to low molecular weight phenols, but rather this enzyme can oxidize accessible tyrosine residues of proteins. Thus, tyrosinase serves to activate proteins for their assembly onto chitosan [99]. Fig. (8b) shows that, when this His-GFP-Tyr protein was studied as a control, it was observed to be soluble at varying $\mathrm{pHs}$ and its fluorescence was independent of $\mathrm{pH}$. When the His-GFPTyr protein was conjugated to chitosan using tyrosinase, theGFP-chitosan conjugate was observed to be soluble at low $\mathrm{pH}$ but to precipitate as the $\mathrm{pH}$ was raised near chitosan's pKa. The conjugate's $\mathrm{pH}$ responsive behavior is illustrated in Fig. (8b) by the series of 


\section{(a)}

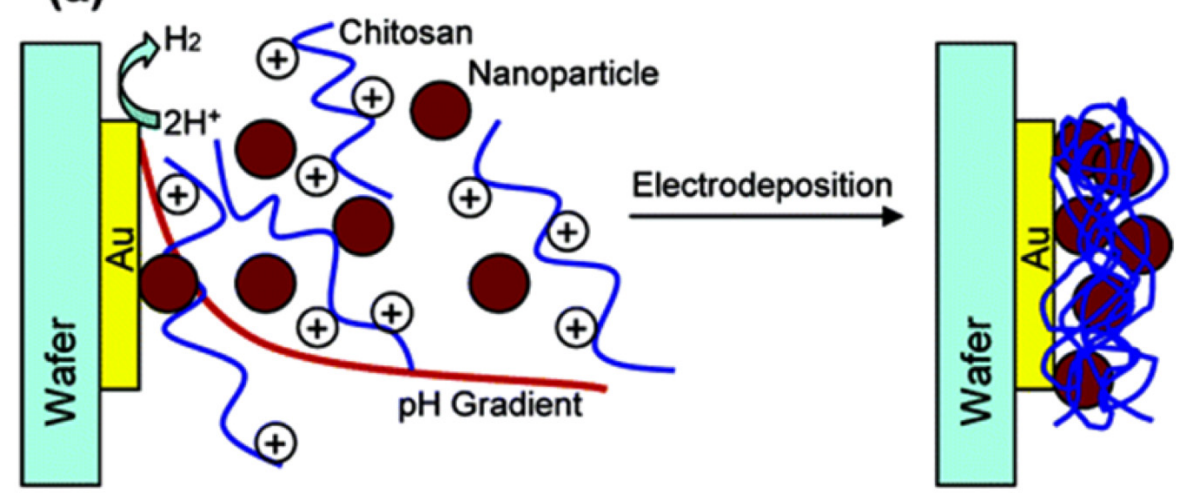

(b)

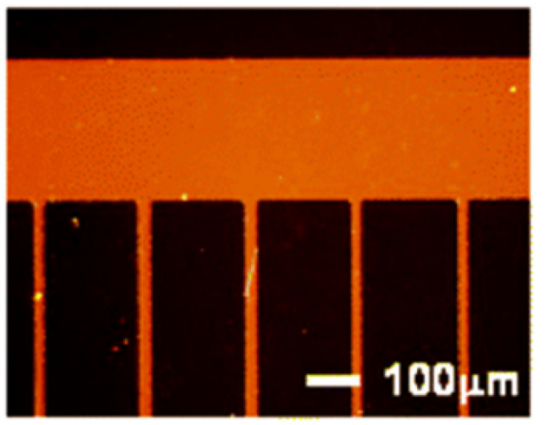

(c)
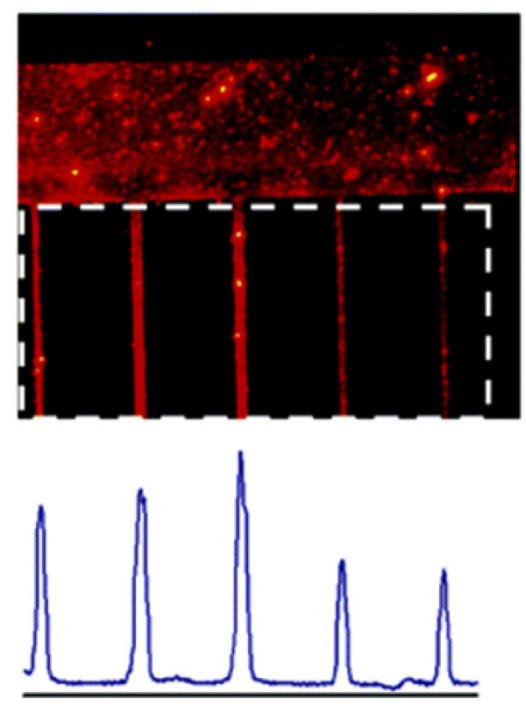

Fig. (7). Electrodeposition of Chitosan can mediate nanoparticle assembly. (a) Mechanism of chitosan-mediated nanoparticle deposited on the cathode. (b) Photomicrograph of silicon wafer patterned with $20 \mu \mathrm{m}$ gold lines for deposition. (c) Fluorescence photomicrograph showing spatially localized deposition of $100 \mathrm{~nm}$ fluorescent latex spheres from a $1 \%$ chitosan solution at $\mathrm{pH}=5$. [98].

fluorescence photographs and the plot of the supernatant's fluorescence versus $\mathrm{pH}[100]$.

\section{CONCLUSIONS}

Chitosan have a wide range of applications. They may be employed, for example, to assist numerous problems in environmental and biomedical engineering. Chitosan is a remarkable chelation agent and create heavy metal traps. In addition, chitosan is biocompatible, shows antimicrobial and antifungic activities which make it a favorable option for biomedical applications. It has been proven to be useful in promoting tissue growth in tissue repair and accelerating wound-healing and bone regeneration. Moreover, chitosan can be incorporated into hydrogels and microspheres which demonstrate large potential in delivery systems for drugs, proteins or genes. In addition, chitosan offers $\mathrm{pH}$-responsivesolubility, external, electrical stimuli, and enzymatic assembly. These capabilities confer considerable versatility to chitosan and suggest this biomaterial has a particularly bright future for various industries.
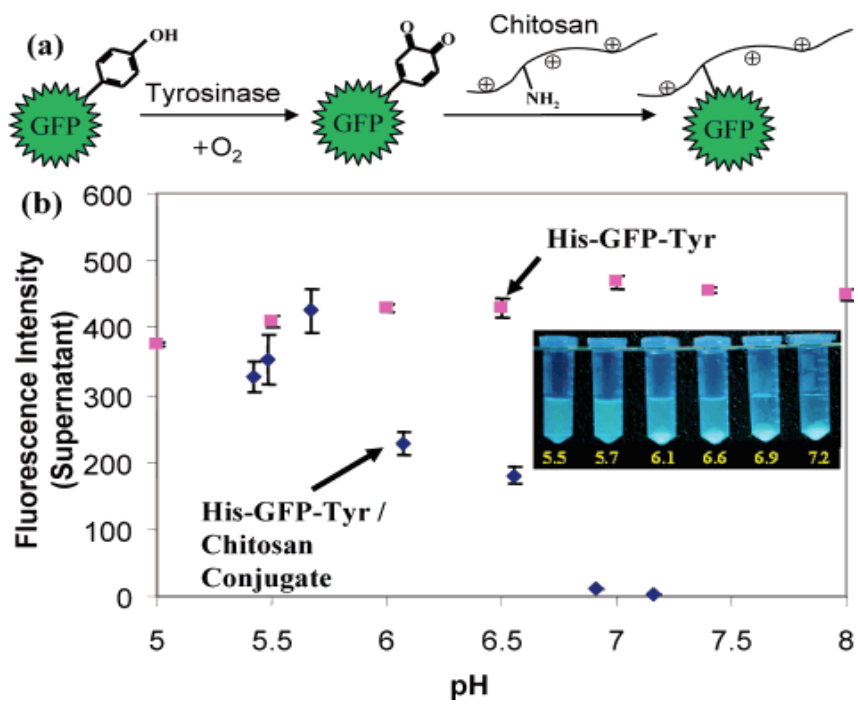

Fig. (8). Enzymatic assembly of proteins onto the backbone of chitosan: (a) Schematic of the tyrosinase-initiated enzymatic assembly of proteins onto chitosan. (b) Conjugation can confer chitosan's pH-responsive solubility to stimulate green fluorescent protein (GFP) [100]. 


\section{ACKNOLWEDGEMENTS}

We thank for the financial support from the 2005-2009 Graduate Student Support Plan (GSSP) in the college of Textiles, NC State University, USA.

\section{REFERENCES}

[1] Hudson SM, Jenkins DW. Chitin and Chitosan in Encyclopedia of Polymer Science and Technology. NJ: Wiley Interscience 2001.

[2] Nishimura S, Kohgo O, Kurita K, Kuzuhara H. Chemospecific manipulations of a rigid polysaccharide synthesis of novel chitosan derivatives with excellent solubility in common organic solvents by regioselective chemical modifications. Macromolecules 1991; 24: 4745-8.

[3] Toffey A, Samaranayake G, Frazier CE, Glasser WG. Chitin derivatives. I. Kinetics of the heat induced conversion of chitosan to chitin. J Appl Polym Sci 1996; 60: 75-85.

[4] Kim SJ, Kim SS, Lee YM. Synthesis and characterization of ether type chitin derivatives. Macromol Chem Phys 1994; 195: 1687-93.

[5] Crini G, Torri G, Guerrini M, Morcellet M, Weltrowski M, Martel B. NMR characterization of N-benzyl sulfonated derivatives of chitosan. Carbohydr Polym 1997; 33: 145-51.

[6] Agboh OC, Qin Y. Chitin and chitosan fibers. Polym Adv Technol 1997; 8(6): 355-65.

[7] Knaul JZ, Creber KAM. Coagulation rate studies of spinnable chitosan solutions. J Appl Polym Sci 1997; 66: 117-27.

[8] Sakamoto M, Tseng H, Furuhata K. Regioselective chlorination of chitin with N-chlorosuccinimide-triphenylphosphine under homogeneous conditions in lithium chloride-N, Ndimethylacetamide. Carbohydr Res 1994; 265: 271-80.

[9] Tseng H, Furuhata K, Sakamoto M. Bromination of regenerated chitin with N-bromosuccinimide and triphenylphosphine under homogeneous conditions in lithium bromide- $\mathrm{N}$, Ndimethylacetamide. Carbohydr Res 1995; 270: 149-61.

[10] Tseng H, Lee R, Furuhata K, Sakamoto M. Bromination of chitin with tribromoimidazole and triphenylphosphine in lithium bromide-dimethylacetamide. Sen'i Gakkaishi 1995; 51: 540-3.

[11] Kurita K, Yoshino H, Yokota K, Ando M, Inoue S, Ishii S, Nishimura S. Preparation of tosyl chitins as precursors for facile chemical modification of chitin. Macromolecules 1992; 25: 378690.

[12] Kurita K, Inoue S, Nishimura S. Preparation of soluble chitin derivatives as reactive precursors for controlled modifications: tosyl- and iodo chitins. J Polym Sci Pol Chem 1991; 29: 937-9.

[13] Luyen DV, Rossbach V. Mixed esters of chitin. J Appl Polym Sci 1995; 55: 679-85.

[14] Qurashi MT, Blair HS, Allen SJ. Studies on modified chitosan membranes. I. Preparation and characterization. J Appl Polym Sci 1992; 46: 255-61.

[15] Qurashi MT, Blair HS, Allen SJ. Studies on modified chitosan membranes. II. Dialysis of low molecular weight metabolites. J Appl Polym Sci 1992; 46: 263-9.

[16] Kubota N. Permeation properties of chitosan transition metal complex membranes. J Appl Polym Sci 1997; 64: 819-22.

[17] Hirano S. A facile method for the preparation of novel membranes from N-acyl and N-arylidene chitosan gels. Agr Biol Chem 1978; 14: 1938-40.

[18] Urbanczyk GW, Lipp-Symonowicz B. The influence of processing terms of chitosan membranes made of differently deacetylated chitosan on the crystalline structure of membranes. J Appl Polym Sci 1994; 51: 2191-4.

[19] Kurita K, Tomita K, Ishii S, Nishimura S, Shimoda K. $\beta$-Chitin as a convenient starting material for acetolysis for efficient preparation of N-acetylchitooligosaccharides. J Polym Sci Pol Chem 1993; 31: 2393-5.

[20] Holme KR, Hall LD. Chitosan derivatives bearing C10-alkyl glycoside branches: a temperature induced gelling Polysaccharide. Macromolecules 1991; 24: 3828-33.

[21] Dvir T, Tsur-Gang O, Cohen S. "Designer" Scaffolds for Tissue Engineering and Regeneration. Isr J Chem 2005; 45: 487-94.

[22] Senel S, McClure SJ. Potential applications of chitosan in veterinary medicine. Adv Drug Deliv Rev 2004; 56(10): 1467-80.

[23] Martino AD. Sittinger M, Risbud MV. Chitosan: a versatile biopolymer for orthopaedic tissue-engineering. Biomaterials 2005; 26: 5983-90.
[24] Li Q, Grandmaison EW, Goosen MFA, Dunn ET. Applications and properties of chitosan. J Bioact Compat Polym 1992; 7(4): 370-97.

[25] Khor E, Lim LY. Implantable applications of chitin and chitosan. Biomaterials 2003; 24(13): 2339-49.

[26] Foda NH, El-Laithy HM, Tadros MI. Implantable biodegradable sponges: effect of interpolymer complex formation of chitosan with gelatin on the release behavior of tramadol hydrochloride. Drug Dev Ind Pharm 2007; 33(1): 7-17.

[27] Senel S, McClure SJ. Potential applications of chitosan in veterinary medicine. Adv Drug Deliv Rev 2004; 56(10): 1467-80.

[28] Wu ACM. Determination of molecular weight distribution of chitosan by high-performance liquid chromatography. J Chromatogr A 1976; 128(1): 87-99.

[29] Beri G, Walker J, Reese ET, Rollings JE. Characterization of chitosans via coupled size-exclusion chromatography and multipleangle laser light-scattering technique. Carbohydr Res 1993; 238: 11-26.

[30] Lee VF. Solution and shear properties of chitin and chitosan. Ph.D. Dissertation, University of Washington, University Microfilms, Ann Arbor, USA, 1974.

[31] Rathke TD, Hodson SM. Review of chitin and chitosan as fibre and film formers. J Macromol Sci Rev Macromol Chem Phys 1994; C34(3): 375-437.

[32] Kumar MNVR. Chitin and chitosan fibres: a review. Bull Mat Sci 1999; 22: 905-15.

[33] Kurita K, Sannan T, Iwakura Y. Studies on chitin. 4. Evidence for formation of block and random copolymers of N-acetyl-Dglucosamine and D-glucosamine by hetero- and homogeneous hydrolyses. Makromol Chem 1977; 178: 3197-202

[34] Kurita K, Koyama Y, Nishimura S, Kamiya M. Facile preparation of water-soluble chitin from chitosan. Chem Lett 1989; 18(9): $1597-8$

[35] Kurita K, Kamiya M, Nishimura S. Solubilization of a rigid polysaccharide: controlled partial $\mathrm{N}$-acetylation of chitosan to develop solubility. Carbohydr Polym 1991; 16: 83-92.

[36] Kang DW, Choi HR, Kweon DK. Selective adsorption capacity for metal ions of amidocimated chitosan bead-g-PAN copolymer. Polymer(Korea) 1996; 20: 989-95.

[37] Kang DW, Choi HR, Kweon DK. Stability constants of amidoximated chitosan-g-poly(acrylonitrile) copolymer for heavy metal ions. J Appl Polym Sci 1999; 73(4): 469-76.

[38] Yang JM, Lin HT, Wu TH, Chen CC. Wettability and antibacterial assessment of chitosan containing radiation-induced graft nonwoven fabric of polypropylene-g-acrylic acid. J Appl Polym Sci 2003; 90(15): 1331-6.

[39] Song SH, Yeom BY, Shim WS, Hudson SM, Hwang TS. Synthesis of biocompatible CS-g-CMS ion exchangers and their adsorption behavior for heavy metal ions. J Ind Eng Chem 2007; 13(6): 100916.

[40] Tojima T, Katsura H, Han SM, Tanida F, Nishi N, Tokura S Preparation of an $\alpha$-cyclodextrin-linked chitosan derivative via reductive amination strategy. J Polym Sci Pol Chem 1998; 36(11): 1965-8.

[41] Sreenivasan K. Synthesis and evaluation of a beta cyclodextrinbased molecularly imprinted copolymer. J Appl Polym Sci 1988; 69(6): 1051-5.

[42] Chen S, Wang Y. Study on $\beta$-cyclodextrin grafting with chitosan and slow release of its inclusion complex with radioactive iodine. J Appl Polym Sci 2001; 82(10): 2414-21.

[43] Aoki N, Nishikawa M, Hattori K. Synthesis of chitosan derivatives bearing cyclodextrin and adsorption of p-nonylphenol and bisphenol A. Carbohydr Polym 2003; 52(3): 219-23.

[44] Madihally SV, Matthew HWT. Porous chitosan scaffolds for tissue engineering. Biomaterials 1999; 20(12): 1133-42

[45] Subramanian A, Vu D, Larsen GF, Lin HY. Preparation and evaluation of the electrospun chitosan/PEO fibers for potential applications in cartilage tissue engineering. J Biomater Sci -Polym Ed 2005; 16(7): 861-73.

[46] Bhattarai N, Edmondson D, Veiseh O, Matsen FA, Zhang MQ. Electrospun chitosan-based nanofibers and their cellular compatibility. Biomaterials 2005; 26(31): 6176-84

[47] Ueno H, Mori T, Fujinaga T. Topical Formulations and Wound Healing Applications of Chitosan. Adv Drug Deliv Rev 2001; 52(2): 105-15. 
[48] Chen J, Chang G, Chen J. Electrospun collagen/chitosan nanofibrous membrane as wound dressing. Colloid Surf APhysicochem Eng Asp 2008; 313-314(1): 183-8.

[49] Jayakumar R, Prabaharan M, Reis RL, Mano JF. Graft copolymerized chitosan-present status and applications. Carbohydr Polym 2005; 62(2): 142-58.

[50] Prabaharan M, Reis RL, Mano JF. Chitosan-based particles as controlled drug delivery systems. Drug Deliv 2005; 12(1): 41-57.

[51] Burns JW, Skinner K, Colt J. Prevention of tissue injury and postsurgical adhesions by precoating tissues with hyaluronic acid solutions. J Surg Res 1995; 59: 644-52.

[52] One K, Saito Y, Yura H, et al. Photocrosslinkable chitosan as a biological adhesive. J Biomed Mater Res Part A 2000; 49(2): 28995.

[53] Hoemann CD, Jun J, Légaré A, McKee MD, Buschmann MD. Osteoarthritis Cartilage 2005; 13(4): 318-29.

[54] Stevens WF, Rao MS, Chandrakranchang S, Eds. Chitin and chitosan: environmental friendly and versatile biomaterials. Bangkok: AIT 1996

[55] Hirano S. Chitin and chitosan as novel biotechnological materials. Polym Int 1999; 48: 732-4.

[56] Teo WE, Ramakrishna S. A review on electrospinning design and nanofibre assemblies. Nanotechnology 2006; 17: R89-106.

[57] Sun T, Xu P, Liu Q, Xue J, Xie W. Graft copolymerization of methacrylic acid onto carboxymethyl chitosan. Eur Polym J 2003; 39(1): 189-92

[58] El-Tahlawy K, Hudson SM. Chitosan: aspects of fiber spinnability. J Appl Polym Sci 2006; 100(2): 1162-8.

[59] Li L, Hsieh YL. Chitosan bicomponent nanofibers and nanoporous fibers. Carbohydr Res 2006; 341(3): 374-81.

[60] Geng XY, Kwon OH, Jang JH. Electrospinning of chitosan dissolved in concentrated acetic acid solution. Biomaterials 2005; 26(27): 5427-32.

[61] Min BM, Lee SW, Lim JN, et al. Chitin and chitosan nanofibers: electrospinning of chitin and deacetylation of chitin fibers. Polymer 2004; 45(21): 7137-42.

[62] Ohkawa K, Cha DI, Kim H, Nishida A, Yamamoto H. Electrospinning of chitosan. Macromol Rapid Commun 2004; 25(18): 1600-5.

[63] Spasova M, Manolova N, Paneva D, Rashkov I. Preparation of chitosan-containing nanofibres by electrospinning of chitosan/poly(ethylene oxide) blend solutions. e-Polymers 2004; 56: $1-12$.

[64] Duan B, Dong C, Yuan X. Electrospinning of chitosan solutions in acetic acid with poly(ethylene Oxide). J Biomater Sci -Polym Ed 2004; 15(6): 797-811.

[65] Jiang HL, Fang DF, Hsiao BJ, Chu BJ, Chen WL. Preparation and characterization of ibuprofen-loaded poly(lactide-co-glycolide)/poly (ethylene Glycol)-g-chitosan electrospun membranes. J Biomater Sci Polym Ed 2004; 15(3): 279-96.

[66] Park WH, Jeong L, Yoo DI, Hudson S. Effect of chitosan on morphology and conformation of electrospun silk fibroin nanofibers. Polymer 2004; 45(21): 7151-7.

[67] Zhang Y, Huang X, Duan B, Wu L, Li S, Yuan X. Preparation of electrospun chitosan/poly(vinyl alcohol) membranes. Colloid Polym Sci 2007; 285(8): 855-63.

[68] Zhou Y, Yang D, Nie J. Electrospinning of chitosan/poly(vinyl alchol)/acrylic acid acrylic solutions. J Appl Polym Sci 2006; 102(6): 5692-7.

[69] Zhou YS, Yang DZ, Nie J. Preparation and characterization of crosslinked chitosanbased nanofibers. Chin Chem Lett 2007; 18(1): 118-20.

[70] Zheng H, Du Y, Yu J, Huang R, Zhang L. Preparation and characterization of chitosan/poly(vinyl alcohol) blend fibers. J Appl Polym Sci 2001; 80(13): 2558-65.

[71] Miya M, Iwamoto R, Mima S. FT-IR study of intermolecular interactions in polymer blends. J Polym Sci Pt B-Polym Phys 1984; 22(6): 1149-51.

[72] Yilmaz E, Erdenizci N, Yilmaz O. Miscibility of chitosan and poly(ethylene oxide) in dilute solution. Int J Polym Anal Charact 2003; 8(5): 327-38.

[73] Son WK, Youk JH. Lee TS, Park WH. The effects of solution properties and polyelectrolyte on electrospinning of ultrafine poly(ethylene oxide) fibers. Polymer 2004; 45(9): 2959-66.
[74] Lin T, Wang H, Wang H, Wang X. The charge effect of cationic surfactants on the elimination of fibre beads in the electrospinning of polystyrene. Nanotechnology 2004; 15: 1375-81.

[75] Lin T, Fang J, Wang H, Cheng T, Wang X. Using chitosan as a thickener for electrospinning dilute PVA solutions to improve fibre uniformity. Nanotechnology 2006; 17: 3718-23.

[76] Jia YT, Gong J, Gu XH, Kim HY, Dong J, Shen XY. Fabrication and characterization of poly (vinyl alcohol)/chitosan blend nanofibers produced by electrospinning method. Carbohydr Polym 2007; 67(3): 403-9.

[77] Deitzel JM, Kleinmeyer J, Harris D, Tan NCB. The effect of processing variables on the morphology of electrospun nanofibers and textiles. Polymer 2001; 42(1): 261-72.

[78] Yang MR, Chen KS, Tsai JC, Tseng CC, Lin SF. The antibacterial activities of hydrophilic-modified nonwoven pet. Mater Sci Eng C 2002; 20: 167-73.

[79] Huh MW, Kang IK, Lee DH, et al. Surface characterization and antibacterial activity of chitosan-grafted poly(ethylene terephthalate) prepared by plasma glow discharge. J Appl Polym Sci 2001; 81(11): 2769-78

[80] Jung KH, Huh MW, Meng W, et al. Preparation and antibacterial activity of PET/chitosan nanofibers. J Appl Polym Sci 2007; 105(5): 2816-23

[81] Chen Z, Mo X, Qing F. Electrospinning of collagen-chitosan complex. Mater Lett 2007; 61(16): 3490-4.

[82] Yi H, Wu L, Bentley WE, Ghodssi R, Rubloff GW, Culver JN, Payne GF. Biofabrication with Chitosan. Biomacromolecules 2005; 6(6): 2881-94.

[83] Murugan R, Ramakrishna S. Nano-featured scaffolds for tissue engineering: a review of spinning methodologies. Tissue Eng 2006; 12(3): 435-47.

[84] Rinaudo M, Pavlov G, Desbrieres J. Influence of acetic acid concentration on the solubilization of chitosan. Polymer 1999; 40: 7029-32.

[85] Sorlier P, Denuziere A, Viton C, Domard A. Relation between the degree of acetylation and the electrostatic properties of chitin and chitosan. Biomacromolecules 2001; 2(3): 765-72.

[86] Strand SP, Tommeraas K, Varum KM, Ostgaard K. Electrophoretic light scattering studies of chitosans with different degrees of $\mathrm{N}$ acetylation. Biomacromolecules 2001; 2(4): 1310-4.

[87] Anthonsen MW, Smidsrod O. Hydrogen-ion titration of chitosans with varying degrees of $\mathrm{N}$-acetylation by monitoring induced ${ }^{1} \mathrm{H}$ NMR chemical-shifts. Carbohydr Polym 1995; 26(4): 303-5.

[88] Varum KM, Ottoy MH, Smidsrod O. Water-solubility of partially $\mathrm{N}$-acetylated chitosans as a function of $\mathrm{pH}$ : Effect of chemical composition and depolymerization. Carbohydr Polym 1994; 25: 6570 .

[89] Montembault A, Viton C, Domard A. Rheometric study of the gelation of chitosan in aqueous solution without cross-linking agent. Biomacromolecules 2005; 6(2): 653-62.

[90] Kurita A. Controlled functionalization of the polysaccharide chitin. Prog Polym Sci 2001; 26: 1921-71.

[91] Katz E, Willner I. Integrated nanoparticle-biomolecule hybrid systems: synthesis, properties, and applications. Angew Chem Int Ed Engl 2004; 43(45): 6042-108.

[92] Fang M, Rant GPS, McShane MJ, Sukhorukov GB, Golub VO, Lvov YM. Magnetic bio/nanoreactor with multilayer shells of glucose oxidase and inorganic nanoparticles. Langmuir 2002; 18(16): 6338-44

[93] Weizmann Y, Patolsky F, Lioubashevski O, Willner I. Magnetomechanical detection of nucleic acids and telomerase activity in cancer cells. J Am Chem Soc 2004; 126(4): 1073-80.

[94] Sarikaya M, Tamerler C, Schwartz DT, Baneyx FO. Materials assembly and formation using engineered polypeptides. Ann Rev Mater Res 2004; 34: 373-408.

[95] Sarikaya M, Tamerler C, Jen AK, Schulten K, Baneyx F. Molecular biomimetics: nanotechnology through biology. Nat Mater 2003; 2(9): 577-85.

[96] Naik RR, Tringer SSJ, Agarwal G, Jones SE, Stone MO. Biomimetic synthesis and patterning of silver nanoparticles. Nat Mater 2002; 1(3): 169-72.

[97] Whaley SR, English DS, Hu EL, Barbara PF, Belcher AM. Selection of peptides with semiconductor binding specificity for directed nanocrystal assembly. Nature 2000; 405(6787): 665-8. 
[98] Wu LQ, Lee K, Wang X, English DS, Losert W, Payne GF. Chitosan-Mediated and Spatially Selective Electrodeposition of Nanoscale Particles. Langmuir 2005; 21(8): 3641-6.

[99] Chen TH, Embree HD, Wu LQ, Payne GF. In vitro proteinpolysaccharide conjugation: Tyrosinase-catalyzed conjugation of gelatin and chitosan. Biopolymers 2002; 64(6): 292-302.
[100] Chen T, Small DA, Wu LQ, et al. Nature-inspired creation of protein-polysaccharide conjugate and its subsequent assembly onto a patterned surface. Langmuir 2003; 19: 9382-6.

(C) Lee et al.; Licensee Bentham Open.

This is an open access article licensed under the terms of the Creative Commons Attribution Non-Commercial License (http://creativecommons.org/licenses/by$\mathrm{nc} / 3.0 /$ ) which permits unrestricted, non-commercial use, distribution and reproduction in any medium, provided the work is properly cited. 